Geografia e Ordenamento do Território, Revista Eletrónica

Centro de Estudos de Geografia e Ordenamento do Território

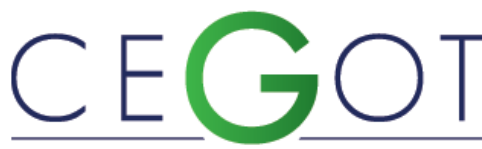

Centro de Estudos de Geografia

e Ordenamento do Território http://cegot.org

ISSN: $2182-1267$

Marques, J.

Faculdade de Letras da Universidade de Coimbra

CEGOT

jorgemarques_18@hotmail.com

Santos, N.

Faculdade de Letras da Universidade de Coimbra

CEGOT

norgeo@ci.uc.pt

\title{
Espaços turísticos e as novas formas de alojamento
}

Referência: Marques, J e Santos, N.. (2012). Espaços turísticos e novas formas de alojamento. Revista de Geografia e Ordenamento do Território, n.ำ 1 (Junho). Centro de Estudos de Geografia e Ordenamento do Território. Pág. 103 a 126

\section{Resumo}

Ao longo dos últimos anos têm-se verificado algumas mudanças na forma como a implementação de novas estruturas de alojamento é levada a cabo e como são "reinventadas" algumas das unidades que se encontram em funcionamento há já algum tempo. Com este trabalho pretende-se explorar o novo enquadramento legal dos empreendimentos turísticos e analisar as principais mudanças ocorridas no panorama do alojamento turístico, num território delimitado pelo Baixo Mondego, Baixo Vouga e Dão-Lafões.

Palavras-Chave: Espaços Turísticos, Alojamento, Investimento, Desenvolvimento Local. 


\section{Abstract}

Over the recent years there have been some changes in how the implementation of new accommodation structures is carried out and how they are "reinvented", mainly those which are in operation for longer. This work aims to explore its new legal framework and analyze the main changes in the panorama of tourist accommodation, in a specific area limited by the Baixo Mondego, Baixo Vouga and Dão-Lafões regions.

Keywords: Tourism Space, Accomodation, Investment, Local Development. 


\section{Um novo paradigma}

Ao longo dos últimos anos têm-se verificado algumas mudanças na forma como a implementação de novas estruturas de alojamento é levada a cabo e como são "reinventadas" algumas das unidades que se encontram em funcionamento há mais tempo. A diversificação na oferta de equipamentos e estruturas de lazer (salas de conferências, spas, entre outros), a inovação tecnológica e a associação de temáticas ou de produtos turísticos ao conceito base é cada vez mais frequente nas unidades hoteleiras como forma de valorização do modelo de negócio e da criação de uma oferta mais competitiva que vá ao encontro das exigências específicas de procura turística cada vez mais segmentada, influenciada pelas alterações que se têm verificado também ao nível do comportamento do consumidor nos últimos tempos, como é preconizado pelo Plano Estratégico Nacional do Turismo (PENT, 2007).

As referidas mudanças no alojamento foram impulsionadas, por um lado, pela implementação do PENT e a disponibilização de apoios ao investimento enquadráveis na implementação ou requalificação de projetos hoteleiros, nomeadamente através do Quadro de Referência Estratégico Nacional (QREN, 2007-2013) e do Programa de Intervenção do Turismo (PIT, 2007-2009) e, por outro, pela entrada em vigor do Decreto-Lei no 39/2008 de 7 de março que veio consagrar o novo regime jurídico da instalação, exploração e funcionamento dos empreendimentos turísticos em Portugal ${ }^{1}$. Este diploma veio introduzir algumas alterações significativas, nomeadamente, a eliminação da classificação de algumas tipologias de empreendimentos até aí existentes como pensões, estalagens, motéis e moradias turísticas, entre outras, e a introdução de um novo conceito denominado alojamento local, criado com o objetivo de agilizar todo o processo burocrático de implementação e exploração de estruturas de alojamento de menor dimensão e de características mais modestas, de tentar combater o número de camas paralelas em Portugal (mais predominante nas zonas costeiras) e de garantir o cumprimento de padrões mínimos de qualidade e segurança

\footnotetext{
${ }^{1}$ Possibilitou a congregação num único decreto as tipologias que outrora estavam divididas vários diplomas (DL no 197/97 Empreendimentos Turísticos; DL no 47/99 - modalidades de hospedagem no Turismo de Natureza; DL nㅇ 256/86 Empreendimentos de Turismo em espaço Rural).
} 
nestas estruturas ${ }^{2}$. Como consequência, tem-se verificado uma reorganização da oferta hoteleira através do aumento de novas tipologias de hotéis que até agora não tinham expressão ou tinham uma representação limitada. O exemplo mais notório verifica-se ao nível da oferta de hostels ${ }^{3}$ e de hotéis de 1 e 2 estrelas, onde se tem constatado um aumento do número destes estabelecimentos devido ao colmatar da lacuna de enquadramento legal até então existente, no caso dos hostels, e ao processo de reconversão que muitas pensões, residenciais, hospedarias e motéis já concluíram, no caso dos hotéis de 1 e 2 estrelas.

Uma análise ao alojamento de um território permite também obter uma perspetiva sobre os diferentes espaços turísticos e suas utilizações e formas de alojamento mais características de cada um deles. Como refere Martins (2004), de acordo com as suas características podem ser identificados cinco tipos principais de espaços de lazer e turismo, nomeadamente o litoral balnear, o rural, a montanha, o urbano e o termal. A estes poderíamos juntar ainda o espaço vitivinícola devido à crescente importância que o enoturismo tem assumido e aos investimentos que tem representado (rotas, museus, empreendimentos, entre outros). Cada um destes espaços representa um conjunto principal de atividades e vivências específicas, traduzindo-se na elaboração de produtos turísticos direcionados para públicos segmentados (Saúde e Bem-estar, Sol e Mar, Turismo de Natureza, Turismo Náutico, Turismo de Aventura, Turismo de Negócios, entre outros). No entanto, verifica-se um esforço por parte dos stakeholders destes destinos na tentativa de adaptar as suas valências a um número mais alargado de públicos, como tem sucedido, por exemplo, no caso dos hotéis termais ou dos hotéis de praia, situados em espaços turísticos vocacionados para públicos muito segmentados, que cada vez mais desenvolvem esforços para a captação de novos públicos e novas utilizações turísticas através da implementação de serviços ou equipamentos complementares e de estratégias de marketing mais diversificadas. Esse facto é bem evidenciado através do produto Turismo de Negócios, mercado-alvo de

\footnotetext{
${ }^{2}$ No total verificou-se a eliminação de pensões, estalagens, motéis, moradias turísticas, turismo rural (TER), casas de abrigo (TER), parques de campismo rural, centros de acolhimento, casas-retiro e turismo de aldeia. As tipologias do novo regime consistem em estabelecimentos hoteleiros (hotéis, hotéis-apartamentos, pousadas), aldeamentos turísticos, apartamentos turísticos, conjuntos turísticos (resorts), empreendimentos de turismo de habitação, empreendimentos de turismo no espaço rural (casas de campo, agroturismo, hotel rural), parques de campismo e caravanismo e empreendimentos de turismo de natureza. $\mathrm{O}$ alojamento local não é considerado empreendimento turístico.

${ }^{3} \mathrm{O}$ equivalente a albergue de juventude.
} 
grande importância estratégica devido às suas características de baixa sazonalidade e maior gasto médio e que cada vez mais tem sido alvo das estratégias de marketing por parte dos hotéis urbanos, de praia, de montanha, termais, entre outros.

Fig. 1 - Contextualização do território em estudo
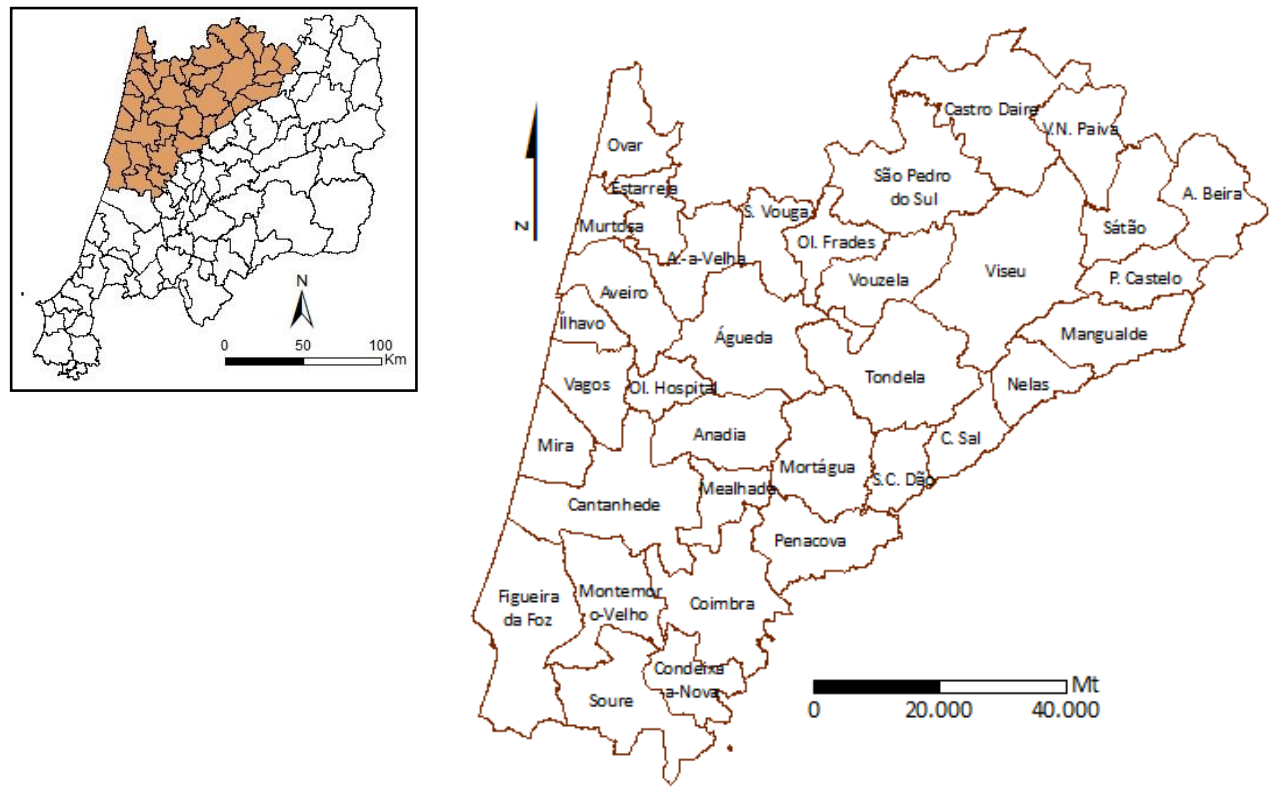

Fonte: Elaboração própria

O Centro Litoral de Portugal conglomera, numa área geográfica delimitada pelo Baixo Mondego, Baixo Vouga e Dão Lafões e que aqui iremos explorar (Fig. 1) ${ }^{4}$, um importante conjunto de fatores que, com o investimento correto e as medidas estratégicas adequadas, poderão ajudar a sustentar o desenvolvimento turístico desta região. Esses fatores englobam a riqueza e diversidade dos atrativos naturais e culturais, a localização geográfica, as acessibilidades, a segurança, a hospitalidade e a vontade política (Marques e Santos, 2011 e 2012). Com este texto pretende-se, por uma lado, evidenciar alguns desses atrativos, merecedores de especial atenção por parte das estratégias de investimento e planeamento turístico e, por outro, fazer uma análise à estrutura de alojamento existente como forma de identificar as potencialidades e debilidades desta componente específica.

\footnotetext{
${ }^{4}$ Este território específico é composto por 35 concelhos e abarca as cidades de Coimbra, Figueira da Foz, Aveiro e Viseu, dotadas de importantes infraestruturas de apoio ao turismo e, mais especificamente, dotados de uma importante oferta hoteleira para a região onde se inserem.
} 


\section{Atrativos turísticos do território em análise (alguns exemplos)}

Nos últimos anos tem sido evidente a crescente atenção que tem sido dada ao património gastronómico e vitivinícola, como elementos diferenciadores para a valorização e promoção turística dos destinos, como é bem evidenciado através do PENT (e do produto estratégico Gastronomia e Vinhos) e do programa Prove Portugal, este último, lançado pelo Turismo de Portugal em junho de 2010 com o principal objetivo de promover a gastronomia e os vinhos nacionais em Portugal e no estrangeiro, através de um Programa de Acão que assenta em três áreas prioritárias de atuação: divulgação e promoção da gastronomia; qualificação dos recursos; e valorização dos produtos (Turismo de Portugal, 2012).

Neste território encontramos uma vasta riqueza gastronómica, de onde podemos salientar um conjunto de famosos pratos típicos como o Leitão Assado à Bairrada, a Caldeirada de Enguias à Moda de Aveiro, o Rancho à Moda de Viseu, a Vitela Assada à Moda de Lafões, o Arroz de Lampreia ou a Chanfana, não deixando de destacar ainda o arroz carolino produzido no Vale do Mondego ou os variados pratos de peixe característicos da beira-mar.

Na doçaria típica (proveniente de uma rica herança da doçaria conventual), para além dos Ovos Moles, podemos destacar o pão de ló de Ovar, os pastéis de Tentúgal, as queijadas de Pereira (Montemor-o-Velho), os pastéis de Lorvão e as Nevadas de Penacova, os pastéis de Vouzela, os pastéis de feijão do Patronato (Mangualde), os pastéis de Santa Clara e o Manjar Branco (Coimbra), entre muitas outras iguarias. Existem também variados produtos abrangidos por diferentes classificações como Denominações de Origem, Indicações Geográficas ou Especialidades Tradicionais, como por exemplo, o Queijo Rabaçal DOP, a Carne Marinhoa DOP, a Carne Arouquesa DOP, a Maçã Bravo de Esmolfe DOP, os já referidos Ovos Moles de Aveiro IGP, o Cabrito da Gralheira IGP, a Maçã da Beira Alta IGP, a Vitela de Lafões IGP ou o Bacalhau de Cura Tradicional Portuguesa ETG (Especialidade Tradicional Garantida), muito característico do concelho de ílhavo. Existem ainda outros produtos que apesar 
de não serem característicos do território específico em análise não deixam de ser considerados como elementos valorizadores desse mesmo território, como é exemplo o Mel da Serra da Lousã DOP ${ }^{5}$. A existência destes tipos de classificações, tal como se verifica no caso dos vinhos e das Regiões Demarcadas, servem de referência à qualidade de produtos que pretendem ser identitários em relação aos territórios onde são produzidos, pela capacidade de promover a integração de produtos turísticos diversos em torno de propostas de grande pertinência para o desenvolvimento local sustentável (Santos e Cunha, 2008).

No que diz respeito à produção vitivinícola, este território é abrangido pelas áreas de Denominação de Origem Controlada da Bairrada, Dão e Lafões e pela sub-região das Terras de Sicó. Como estratégia para o desenvolvimento do enoturismo no território foram inclusivamente criadas duas rotas, nomeadamente a Rota do Vinho do Dão e a Rota do Vinho da Bairrada. Na Bairrada, e mais precisamente em Anadia (cidade também conhecida como "capital do espumante"), para além da existência de um museu dedicado à produção vitivinícola (Museu do Vinho da Bairrada) existe ainda o Espaço Bairrada - Wine Tourism and Passion Store, que consiste no espaço utilizado pela Associação Rota da Bairrada para a promoção da respetiva região e dos seus produtos típicos, encontrando-se a funcionar no antigo edifício da Estação de Caminhos de Ferro da Curia que foi recuperado para o efeito. Em Nelas existe também um museu dedicado ao vinho da região (Museu do Vinho do Dão), que ajuda a contribuir para o desenvolvimento do produto turístico associado ao enoturismo através da valorização da imagem da Região do Dão.

No que diz respeito à oferta termal, contabilizam-se nove espaços termais (Fig. 2): na região de Viseu, localizam-se as termas de Sangemil (Tondela), Felgueira (Nelas), Alcafache (Mangualde), Cavaca (Aguiar da Beira), São Pedro do Sul e Carvalhal (Castro Daire); na região da Mealhada/Anadia localizam-se as termas do Luso (Mealhada), Curia e Vale da Mó (Anadia).

\footnotetext{
${ }^{5}$ Os concelhos integrantes do Pinhal Interior Norte apesar de não fazerem parte do território específico em análise, não deixam de representar um grande potencial de valorização desse mesmo território e que terá de ser considerado. A título de exemplo, frequentemente os programas sociais de congressos realizados na cidade de Coimbra contemplam visitas a este território, veja-se o caso do Congresso Internacional Turismo Lazer e Cultura, realizado entre 27 e 29 de setembro e que contemplou, entre outras atividades, um passeio pedestre na serra da Lousã.
} 


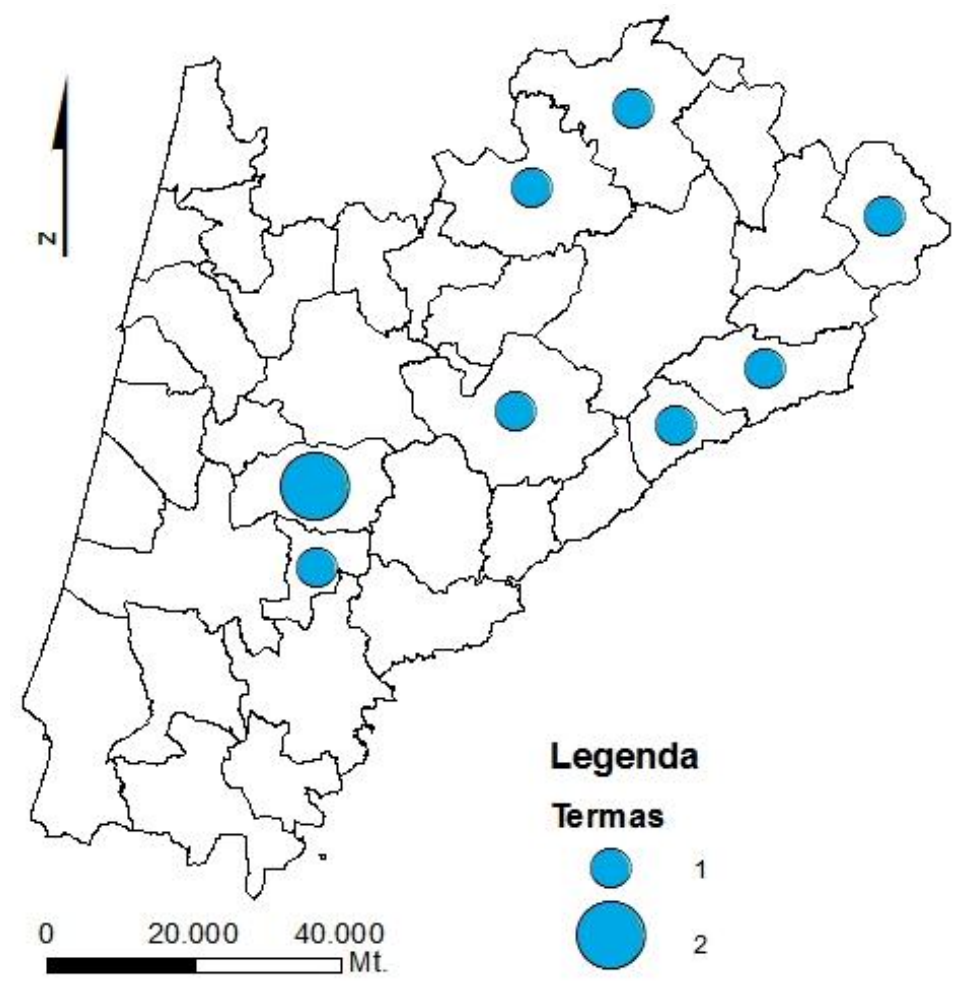

Fonte: Termas de Portugal, 2012

Pela sua importância podemos destacar as termas de São Pedro do sul, que recebem cerca de 20.000 aquistas por ano, o que as torna nas mais procuradas no país, as termas da Curia, inseridas numa área de cerca de 14 hectares da qual fazem parte um hotel (Hotel das Termas) e um campo de golfe (Campo de Golfe da Curia), e as termas do Luso, com um novo modelo de gestão através da elaboração de uma parceria com a empresa Malo Clinic que originou uma diversificação da oferta. Neste caso passou a abranger o termalismo clássico, a vertente do spa e a vertente médica, que à partida resultará numa maior rentabilização do espaço e maior abrangência de público-alvo. É também pertinente a associação destes espaços a fatores históricos e culturais que, por sua vez, valorizam a imagem do destino turístico. As termas de São Pedro do Sul são também conhecidas por terem sido frequentadas por D. Afonso Henriques que aí curou uma fratura numa perna após a Batalha de Badajoz, enquanto as termas do Luso evocam um dos grandes nomes da arquitetura portuguesa do Estado Novo ${ }^{6}$ que foi

\footnotetext{
${ }^{6}$ Estilo arquitetónico também conhecido como Estilo Português Suave, Estilo Nacionalista ou Estilo Tradicionalista.
} 
Cassiano Branco, autor do Grande Hotel do Luso e do Portugal dos Pequenitos, entre outras obras.

Quanto aos espaços naturais, a região possui um vasto património, incluindo vários elementos inseridos na Rede Nacional de Áreas Protegidas (Reservas Naturais, Paisagens Protegidas e Sítios Classificados) (Fig. 3) e na Rede Natura 2000 (Zonas de Proteção Especial e Sítios de Importância Comunitária) (Fig. 4). A grande diversidade geográfica e paisagística pode-se constatar nas praias da costa litoral do Baixo Vouga e Baixo Mondego, no Baixo Vouga Lagunar (projeto BioRia ${ }^{7}$ ) e Estuário do Mondego, nas Pateiras de Frossos e Fermentelos (sendo esta considerada uma das maiores lagoas naturais da Península Ibérica), nos Pauis de Arzila, Madriz e Taipal, na Reserva Natural das Dunas de São Jacinto, nas falésias do Cabo Mondego, nos leitos e praias fluviais dos rios Mondego e Vouga e seus afluentes, nas serras da Boa Viagem, Sicó, Buçaco, Caramulo, Montemuro, Freita, Arada e Lapa, na Mata Nacional do Buçaco, no Parque Botânico Arbustus do Demo, em Vila Nova de Paiva, no Bioparque de S. Pedro do Sul, na Cascata da Cabreia, proveniente do rio Mau e localizada em Sever do Vouga, no Jardim Botânico e na Mata Nacional do Choupal, em Coimbra.

Todos estes lugares proporcionam um grande potencial para o desenvolvimento de atividades de lazer e recreio, que podem ir desde os passeios pedestres, em bicicleta (BTT) ou em jipe (TT), ao birdwatching, às atividades náuticas e até a atividades mais aventureiras, como escalada, rappel, slide, parapente ou espeleologia. Aqui, as empresas de animação turística desempenham um papel muito importante, na medida em que se posicionam como agentes dinamizadores, ajudando a valorizar estes e outros espaços naturais. A importância das praias marítimas e fluviais, das ciclovias e o desenvolvimento da atividade equestre assumem aqui também uma grande importância.

\footnotetext{
${ }^{7}$ Rede de Percursos Pedestres e Cicláveis e Centro de Interpretação Ambiental implementados no Baixo Vouga Lagunar, mais precisamente no concelho de Estarreja (freguesias de Beduido, Salreu e Canelas) implementados com o objetivo de valorizar um importante ecossistema natural com uma vasta biodiversidade faunística e florista que abarca ambientes aquáticos e terrestres, os Rios Antuã, Jardim e Gonde, os arrozais, o campo "Bocage" e campos agrícolas, em plena harmonia com habitats de transição como sapais, caniçais, lamas entre marés e juncais.
} 
Fig. 3 - Concelhos abrangidos pela Rede Natura 2000.

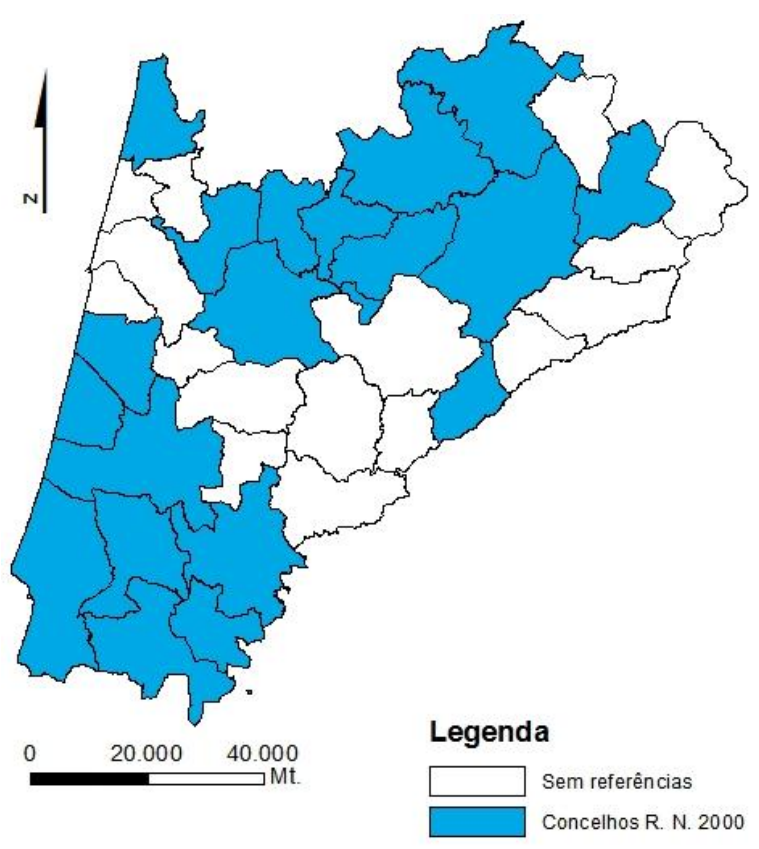

Fonte: ICNB, 2012

Fig. 4 - Concelhos abrangidos pela Rede Nacional de Áreas Protegidas.

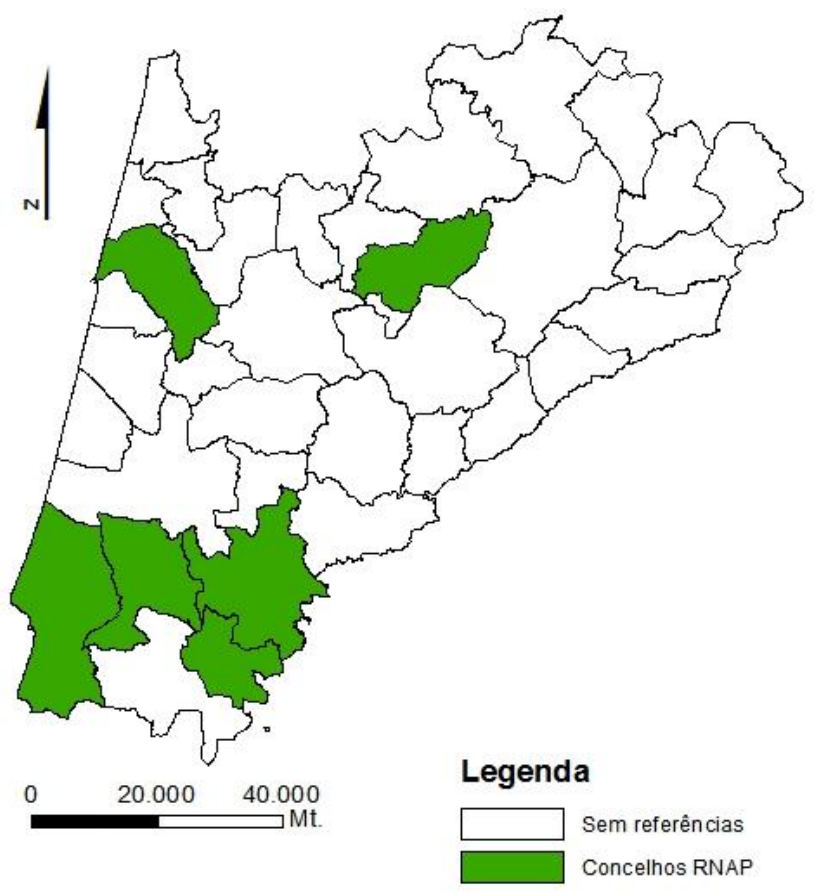

Fonte: ICNB, 2012. 
Toda a costa marítima juntamente com as bacias hidrográficas dos rios Vouga e Mondego apresentam boas condições para a prática de atividades náuticas marítimas e fluviais, lúdicas e desportivas. Para além dos passeios de barco na "ria" de Aveiro (nos famosos barcos moliceiros) e no rio Mondego (Basófias), existem outras atividades que podem ser realizadas como a canoagem, a vela, o remo, o surf, o windsurf, o kitesurf, o bodyboard, o mergulho, a pesca desportiva e a motonáutica, entre outras. Relativamente a infraestruturas para embarcações, para além dos principais portos marítimos da região (Aveiro e Figueira da Foz), existem outros cais de acostagem para pequenas e médias embarcações, possibilitando o desenvolvimento das atividades enumeradas.

Nas ciclovias, que têm surgido como forma de valorização de centros urbanos e não urbanos, importa destacar dois importantes investimentos recentes neste campo. Um deles consiste na Ecopista do Dão. Inaugurada oficialmente em 2011 e considerada a maior via ciclável do país, unindo Viseu, Tondela e Santa Comba Dão num percurso de cerca de $50 \mathrm{~km}$, foi construída através do reaproveitamento do antigo Ramal do Dão, linha ferroviária que estava desativada há cerca de duas décadas. O outro consiste na Ciclovia do Mondego, projeto que se encontra na sua fase inicial de investimento e que pretende ligar os concelhos de Coimbra, Montemor-o-Velho e Figueira da Foz num troço de cerca de $41 \mathrm{~km}$ ao longo do rio Mondego e que vai possibilitar um maior desenvolvimento de atividades de lazer e o rejuvenescimento da área ribeirinha entre Coimbra e Figueira da Foz.

No que diz respeito à atividade equestre, conforme é referido pelo Turismo de Portugal (2008):

“podemos, pois, dizer que a consolidação de uma oferta turística no domínio do turismo equestre - seja no contexto do turismo natureza (fruição dos espaços naturais e das zonas rurais), do touring cultural e paisagístico (descoberta dos "sítios", do património, das tradições - como é o caso da tradição equestre), do sol e mar, do turismo de saúde e bem-estar, ou numa ótica mais especializada dos eventos desportivos ou do desenvolvimento das raças - se deverá assumir como uma oportunidade nas estratégias de desenvolvimento turístico nacional e regionais no 
sentido em que se constitui como um efetivo qualificador da oferta capaz de potenciar a atratividade dos destinos."

A atividade equestre é cada vez mais é associada ao Turismo de Natureza e à valorização das atividades ao ar livre, proporcionando uma interessante forma de conhecer a envolvência natural da região e de valorização e desenvolvimento local, especialmente importante para os meios não urbanos.

Fig. 5- Centros hípicos

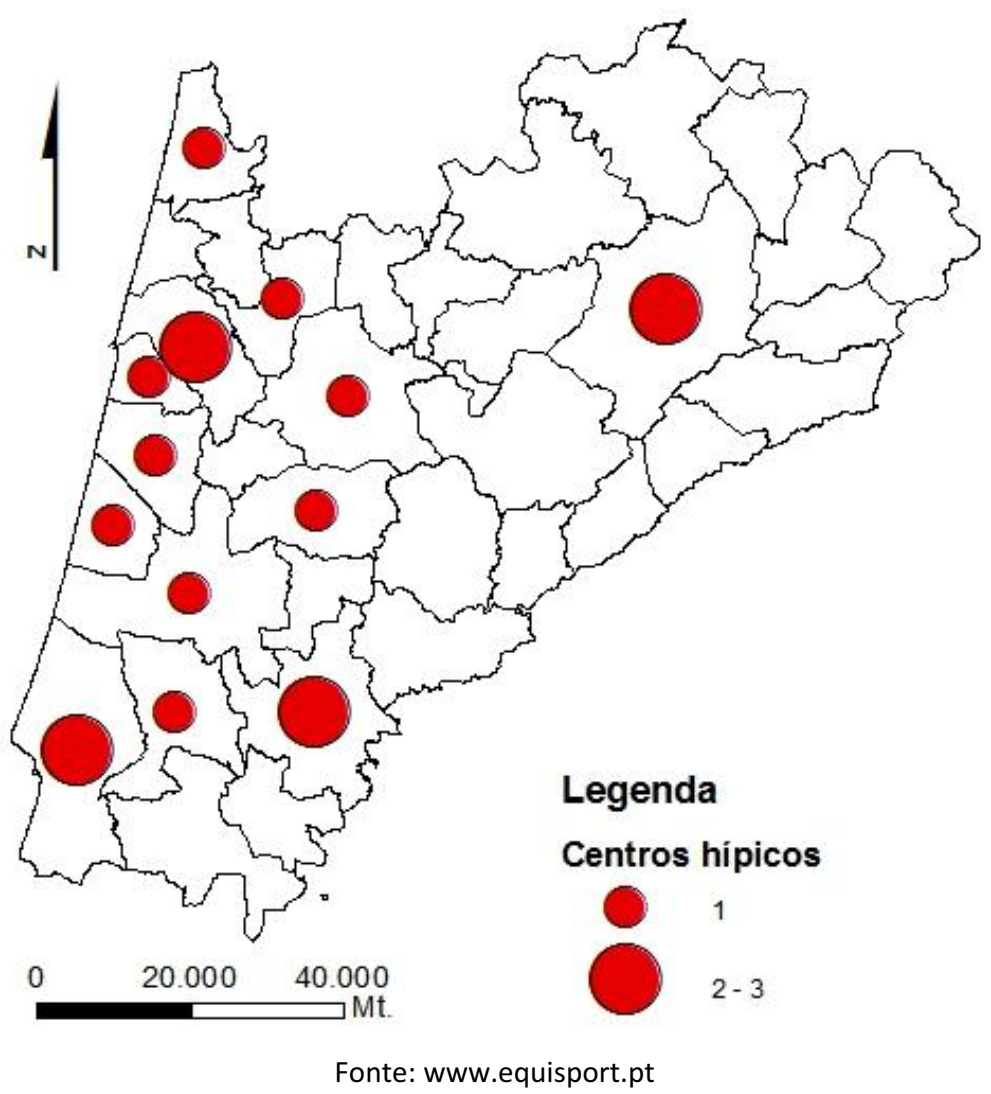

Atualmente são inúmeros os locais dedicados à atividade equestre que podemos encontrar na região (Fig. 5), destacando-se os concelhos de Aveiro, Viseu, Figueira da Foz e Coimbra, com a maior oferta.

O território em estudo apresenta ainda outros elementos integrantes da sua valiosa herança histórico-cultural, de onde se evidencia o Fado de Coimbra, cantado pelas ruas, praças e casas de fado típicas da cidade (bem como em novos espaços culturais 
criados para o efeito como o À Capella ${ }^{8}$ e o Fado ao Centro ${ }^{9}$ ), as tradições académicas de Coimbra e Aveiro (com o maior peso para a Latada e a Queima das Fitas da Universidade de Coimbra), a arte xávega presente em diversas povoações costeiras do Baixo Vouga e Baixo Mondego, o cultivo artesanal dos campos de arroz no Baixo Mondego e no Baixo Vouga Lagunar, a herança histórica deixada pela atividade ambulante dos ourives de Cantanhede (de onde terão partido na década de 60 os primeiros ourives ambulantes que deram origem proliferação das atuais ourivesarias um pouco por todo o país) e a arte ancestral de trabalhar a pedra de Ançã, característica da região de Cantanhede e representada na torre da Universidade de Coimbra ou nos túmulos dos reis D. Afonso Henriques e D. Sancho I (que podem ser vistos na Igreja de Santa Cruz), entre muitos outros testemunhos. Também os nomes de figuras históricas ligadas à região, como escritores (Carlos de Oliveira, Fernando Namora ou Miguel Torga), artistas (José Afonso, Carlos Paredes) e outras personalidades, como o navegador, explorador e escritor Fernão Mendes Pinto, o médico Egas Moniz (primeiro Nobel português), o famoso diplomata Aristides de Sousa Mendes, ou Pedro e Inês (protagonistas da famosa lenda associada fortemente à Quinta das Lágrimas), contribuem para um importante peso histórico-cultural que importa valorizar. Alguns espaços museológicos foram, inclusivamente, criados com esse propósito, como por exemplo, a Casa Museu Egas Moniz, a Casa Museu Miguel Torga ou Casa Museu Fernando Namora.

Ao analisarmos a distribuição do património imóvel classificado pelo $\operatorname{IGESPAR}^{10}$, podemos verificar que os concelhos de Coimbra e Figueira da Foz são aqueles que contabilizam o maior número de elementos classificados, seguindo-se os concelhos de Montemor-o-Velho, Aveiro, Tondela, Viseu e Mangualde (Fig. 6). O concelho de Vagos é o único que não possui elementos classificados, o que não quer dizer que não possua locais de interesse cultural, como é evidenciado através da existência de um conjunto

\footnotetext{
${ }^{8}$ Casa de Fados e centro cultural que resultou da recuperação da Capela de Nossa Senhora da Vitória, inaugurado em junho de 2003.

${ }^{9}$ Casa de Fados e centro cultural inaugurado em julho de 2011.

${ }^{10}$ Aqui foram incluídos todos os elementos patrimoniais arquitetónicos civis, arquitetónicos religiosos, arquitetónicos militares e arqueológicos classificados ou em vias de classificação.
} 
de moinhos (Moinhos de Vento de São Romão), pelourinhos, capelas, igrejas e casas brasonadas.

Na cidade de Coimbra importa destacar o conjunto patrimonial da Universidade de Coimbra $^{11}$, a Igreja do Mosteiro de Santa Cruz, com estatuto de Panteão Nacional atribuído em 2003 devido à presença tumular dos dois primeiros reis de Portugal, D. Afonso Henriques e D. Sancho I, o Mosteiro de Santa Clara - a - Velha recuperado recentemente depois de permanecer submerso pelas águas do Mondego durante séculos, a Sé Nova e a Sé Velha. Também o património arqueológico do Museu Monográfico de Conímbriga, em Condeixa-a-Nova, merece destaque pela sua importância histórica e patrimonial. Já na Figueira da Foz, podemos destacar, entre outros, a Fortaleza de Buarcos, a Casa do Paço, o Mosteiro de Santa Maria de Seiça e o Paço de Maiorca, onde há muito está prevista a transformação em hotel de luxo, mantendo as características do edifício ${ }^{12}$.

Fig. 6 - Distribuição do património classificado, por concelho.

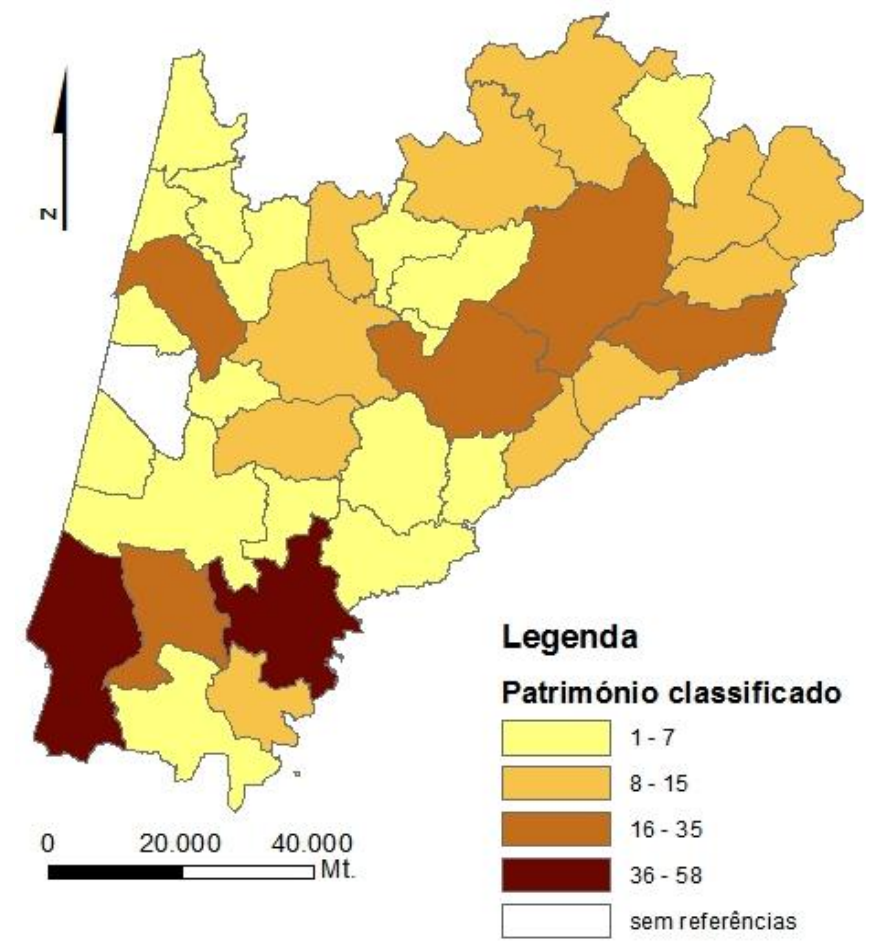

Fonte: IGESPAR, 2012

\footnotetext{
${ }^{11}$ A Universidade de Coimbra apresentou em 2010 a candidatura a Património Mundial da UNESCO, com uma área patrimonial que inclui o Núcleo do Paço das Escolas, o Núcleo dos Colégios Universitários, o Núcleo da Reforma Pombalina, o Núcleo do Estado Novo, o Núcleo das repúblicas, entre um conjunto de outros edifícios relevantes.

12 Este projeto tem sofrido alguns contratempos, havendo mesmo dúvidas neste momento sobre a possibilidade a sua implementação.
} 
Na região de Viseu, historicamente associada à figura do herói lusitano Viriato e onde se pode encontrar a Cava de Viriato (vestígios de uma estrutura defensiva romana em forma de polígono com mais de $2 \mathrm{~km}$ de perímetro), predomina também um importante património histórico, bastante evidenciado no centro da cidade de Viseu num conjunto que engloba o adro da Sé (onde podemos encontrar a Varanda dos Cónegos e Torre de Menagem, a Sé Catedral, o Museu Grão Vasco e a Igreja da Misericórdia) e o rossio (Paços do Concelho, Igreja dos Terceiros, Painel de Azulejos ao longo do muro do Jardim das Mães, Casa Museu Almeida Moreira), entre muitos outros pontos de interesse espalhados pela cidade. A região de Viseu é também caracterizada pela existência de um vasto número de solares e as casas apalaçadas, muitas vezes rentabilizadas através da conversão em espaços de alojamento associados ao turismo de natureza.

Na região de Aveiro, por sua vez, podemos encontrar um conjunto patrimonial rico em edifícios do estilo Arte Nova. Apesar de existirem importantes testemunhos deste estilo arquitetónico noutros lugares, como Ovar (também conhecida como cidademuseu do azulejo), Anadia (evidenciada através do Curia Palace Hotel) ou Figueira da Foz (como por exemplo alguns edifícios do Bairro Novo de Santa Catarina), é na cidade de Aveiro que podemos encontrar o maior número de testemunhos deste estilo arquitetónico e onde se situa o Museu de Arte Nova. A extinta Região de Turismo Rota da Luz criou, inclusivamente, a Rota da Arte Nova (limitada ao Baixo Vouga) que para além de Aveiro incluiu Ovar, Avanca, Estarreja, Salreu, Albergaria - a - Velha, Frossos e Ílhavo.

Destacamos ainda outros elementos como o núcleo de moinhos da Serra da Atalhada na região de Penacova (tendo sido recuperados alguns deles para alojamento de Turismo Rural), o Caminho Português de Santiago que passa entre Condeixa-a-Nova e Albergaria-a-Velha e que abrange inúmeras capelas e igrejas ao longo do trajeto, a rota dos castelos do Mondego (que abarca Coimbra, Figueira da Foz, Lousã, Montemor-oVelho, Penela e Soure) e a rota das muralhas e torres de Dão Lafões (Viseu, Aguiar da Beira, Vouzela e Mangualde), a rota dos palheiros característicos das praias da Costa Nova, Tocha e Mira ou o centro mineiro que inclui as minas do Braçal, da Malhada e do Coval da Mó, em Sever do Vouga. Neste último caso, o património existente encontra- 
se em total estado de abandono e degradação. O testemunho da atividade mineira merecia, no entanto, ser reavivado, necessitando para isso de investimento estruturado e planeado e que poderia resultar num produto relacionado com o Turismo Industrial, à semelhança do que já vai acontecendo noutras áreas geográficas, como São João da Madeira e Marinha Grande, entre outras. Ao falar de investimento e de recuperação de património, não podemos deixar de apresentar os bons exemplos que são as Aldeias do Xisto e as Aldeias Históricas de Portugal. Apesar de não estarem inseridas na delimitação geográfica do território em estudo, posicionam-se também como produtos estratégicos complementares devido à sua proximidade e, por isso, facilmente acessíveis a quem se deslocar a este território.

Todos os elementos explorados até aqui desempenham um papel importante na organização e promoção da oferta turística da região, muitas das vezes estruturada pelos municípios ou entidades turísticas locais sob a forma de percursos ou rotas turísticas e onde o artesanato também tem grande importância ao possibilitar, por um lado, a perpetuação da memória dos lugares por parte dos visitantes e, por outro, o desenvolvimento do comércio local.

\section{Distribuição da oferta de alojamento}

Ao analisarmos a distribuição do alojamento no território, podemos verificar alguns aspetos relevantes (Fig. 7). O concelho com maior número de empreendimentos turísticos, número de quartos e número de camas coincide com a localização do principal centro urbano da região: a cidade de Coimbra. A sua imagem turística indissociável da Universidade dá-Ihe o estatuto de principal destino turístico de todo o território, com maior número de visitantes, para além da maior oferta hoteleira. Aqui o Turismo Cultural assume especial relevância, no entanto, também o Turismo de Negócios merece destaque pela crescente atenção de que tem sido alvo por parte dos principais stakeholders. A importância deste produto é evidenciada através da presença da cidade de Coimbra no ranking da Internacional Congress and Convention Associacion (ICCA) e reforçada através da abertura do Hotel Vila Galé Coimbra, em 2010, com a classificação de 4 estrelas e um conceito de Leisure \& Conference (lazer e 
negócios), sendo considerado o maior hotel localizado entre Lisboa e Porto, com 229 quartos.

Um segundo aspeto relevante é a oferta de alojamento nos espaços do litoral balnear. Apesar de toda a costa marítima deste território apresentar condições naturais favoráveis para a prática do denominado turismo de Sol e Mar, é nos concelhos de Aveiro e Figueira da Foz que existe um maior número de estruturas hoteleiras e serviços complementares. Para além das inúmeras praias, estes concelhos possuem os dois principais portos marítimos da região que possibilitam a acostagem de pequenas e médias embarcações de recreio e que se afiguram como estruturas importantes para a prática de desportos náuticos, como barco à vela, surf, windsurf, motonáutica, entre outros. No entanto, importa destacar a Figueira da Foz por ser aqui que se encontra o maior número de estabelecimentos hoteleiros localizados na primeira linha de costa. Aqui também é bem evidente o investimento que tem sido feito na requalificação hoteleira, de onde podemos destacar a construção em curso do hotel Holiday Inn Figueira da foz, com previsão de abertura para 2013 (tendo sofrido já alguns atrasos na sua construção) e que contará com 160 quartos, 11 salas de reuniões, 1 anfiteatro e 1 salão para banquetes e eventos, entre outros serviços. O número significativo de salas de reuniões evidencia a atenção dada ao Turismo de Negócios, como produto complementar ao Sol e Mar. 
Fig. 7 - Distribuição da oferta de alojamento, por concelho.
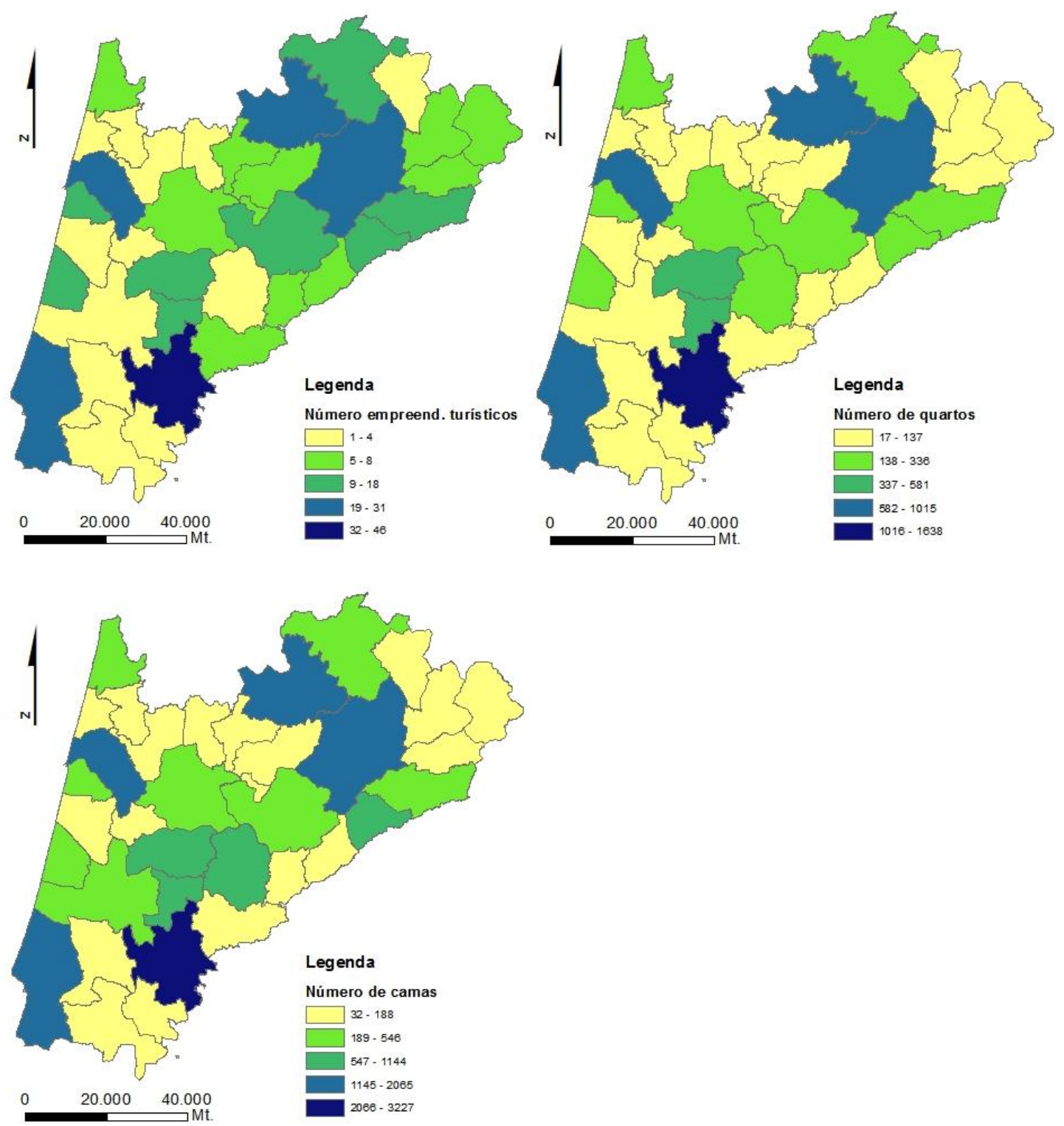

A - Número de empreendimentos turísticos; B - Número de quartos; C - Número de camas Fonte: www.maisturismo.pt

Um terceiro aspeto relevante consiste na oferta de alojamento nos espaços termais e vitivinícolas e que praticamente coincidem em duas regiões distintas. Por um lado, a região termal da Mealhada/Anadia que coincide com parte da região da Bairrada, destacando-se a oferta de alojamento nos concelhos de Mealhada e Anadia. Por outro, a região termal de Viseu que coincide com parte da região vitivinícola do Dão, destacando-se a oferta de alojamento nos concelhos de Viseu e São Pedro do Sul. No caso dos destinos termais, podemos identificar unidades de alojamento com 
referências claras ao produto Saúde e Bem-estar (hotéis termais, hotéis com spas ${ }^{13}$ ). No entanto, o mesmo não se verifica relativamente ao enoturismo, onde ainda não existem estruturas hoteleiras a atuar em força especificamente neste segmento, ao contrário do que já acontece noutros pontos do país, como por exemplo em Vila Nova de Gaia (The Yeatman Oporto Hotel, unidade de 5 estrelas inaugurada em 2010), em Montemor-o-Novo (L'AND Vineards, wine resort de luxo inaugurado em 2011), em Sabrosa (Casa das Pinas - Quinta do Portal, unidade de agroturismo inaugurada em 2011 e Quinta Nova de Nossa Senhora do Carmo $^{14}$, hotel rural de 4 estrelas inaugurado em 2005) e no Funchal (Hotel The Vine, unidade de 5 estrelas inaugurada em 2009), entre outros. Através destes casos, podemos verificar uma tendência crescente nos últimos anos na aposta estratégica junto deste segmento e o seu posicionamento junto de um perfil de turistas com maior poder de compra.

Por último, importa realçar o concelho de Mortágua que, por um lado, apresenta-se como um dos concelhos com menor número de empreendimentos mas, por outro, como um dos que apresentam maior número de camas. Este facto deve-se à existência, do aldeamento turístico Montebelo Aguieira Lake Resort \& Spa que foi inaugurado em 2009. Trata-se de uma unidade de 5 estrelas que integra a cadeia Montebelo Hotels \& Resorts (do grupo Visabeira, com sede em Viseu) ${ }^{15}$, situada junto à Barragem da Aguieira, localizada estrategicamente entre Viseu e Coimbra, com uma área de cerca de 35 hectares onde se inclui uma marina fluvial com 400 postos de amarração (para embarcações a motor, à vela e a remos), um ginásio, duas piscinas (uma interior e outra exterior), um Spa e um salão de eventos onde poderão ser realizadas reuniões de negócios até cerca de 400 pessoas, entre outros eventos. Contabiliza 152 habitações e mais de 300 quartos, distribuídos por apartamentos e villas. Este importante espaço, vocacionado especialmente para o Turismo Náutico, de

\footnotetext{
${ }^{13}$ Como por exemplo, Curia Palace Hotel Spa \& Golf, Grande Hotel da Curia Golf \& Spa, Hotel das Termas da Curia, Hotel do Parque Health Club \& Spa.

${ }^{14}$ Considerado o primeiro hotel vínico de Portugal.

${ }^{15}$ Das cindo unidades de 5 estrelas existentes na região, quatro delas pertencem ao grupo Montebelo (Hotel Montebelo e Palácio dos Melos em Viseu, Montebelo Aguieira e Hotel Casa da Insuã). A outra unidade de 5 estrelas consiste no Buçaco Palace Hotel, com 64 quartos, situado no interior na Mata Nacional do Buçaco. É atualmente explorado pelo grupo Hotéis Alexandre de Almeida que possui também na região o Curia Palace Hotel Spa \& Golf e o Hotel Astória Coimbra, de 3 estrelas, com 60 quartos e duas suítes, situado em frente ao rio Mondego, muito próximo da baixa comercial da cidade de Coimbra e da Estação Nova (estação ferroviária Coimbra A).
} 
Saúde e Bem-estar e de Natureza, não deixa de apontar as estratégias de marketing para a captação do Turismo de Negócios através da promoção das suas instalações e, mais especificamente, do seu salão de eventos ${ }^{16}$, representando, no seu todo, um importante fator de dinamização da economia local.

Fig. 8 - Distribuição dos empreendimentos, por tipologia, por concelho
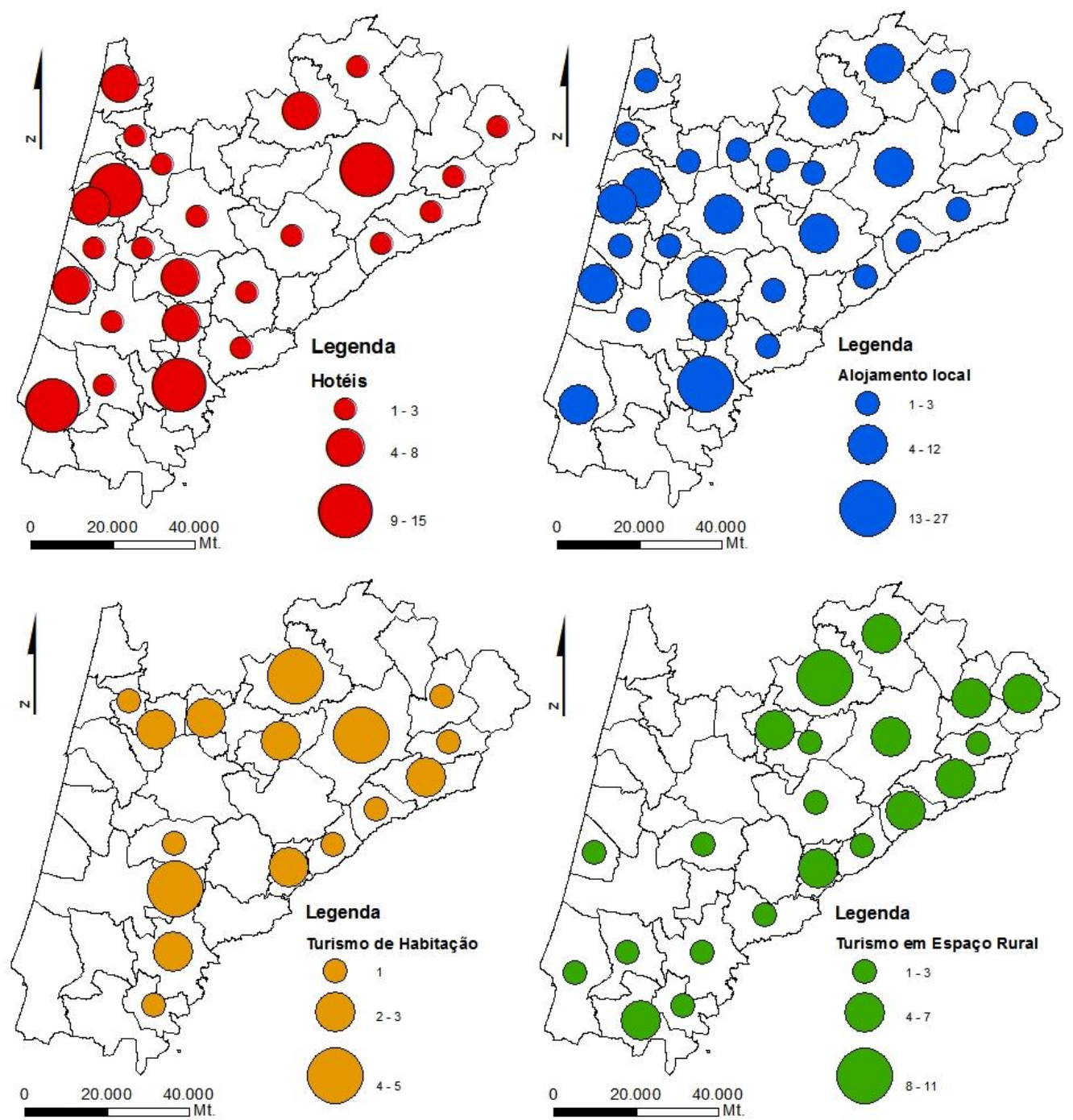

A - Hotéis; B - Alojamento local; C - Turismo de habitação; D - Turismo em espaço rural

Fonte: www.maisturismo.pt

Podemos constatar também que é nos espaços rurais e de montanha, destinos com menor densidade populacional, com uma atividade turística menos massificada e que englobam um conjunto de atividades e produtos turísticos mais relacionados com as atividades ao ar livre e o usufruto da natureza, que encontramos uma menor oferta de estabelecimentos hoteleiros tradicionais (hotéis, apart-hotéis) - Fig.8. No entanto,

\footnotetext{
${ }^{16}$ Como se pode constatar através do seu sítio de Internet: http://www.montebeloaguieira.pt/.
} 
estes espaços conglomeram uma maior oferta de outros tipos de alojamento, nomeadamente os estabelecimentos de Turismo em Espaço Rural e os estabelecimentos de Turismo de Habitação, caracterizados por terem menores dimensões o que se reflete ao nível do número de quartos e do número de camas. Já a oferta de Alojamento Local, onde incluímos todas as tipologias extintas e que ainda não concluíram o processo de reconversão, verifica-se uma dispersão por toda a região e seguindo a tendência de maior concentração nos principais centros urbanos, termais e costeiros.

\section{Considerações Finais}

O território em análise apresenta um importante conjunto de elementos patrimoniais naturais e culturais que poderão contribuir para o desenvolvimento económico local através do desenvolvimento de atividades ligadas ao turismo e ao lazer. Neste sentido, as estruturas de alojamento significam um importante fator de suporte (e que por vezes poderão representar por si só um forte motivo de interesse turístico) que importa valorizar. Por vezes possibilitam ainda a recuperação de património devoluto, que se traduz na recuperação de valores culturais e históricos para as populações locais.

A região tem contado com importantes investimentos nos últimos anos, contrariando um pouco os tempos adversos que a economia nacional atravessa, o que nos reforça a ideia de que o turismo é um setor muito importante para o desenvolvimento económico local. A crescente tendência para associar designações complementares aos nomes que os empreendimentos adotam (Palace, Spa, Golfe, Lake Resort, Art Nouveau \& Design, Boutique, Beach \& Spa, entre outros) mostra também uma tendência clara para chamar a atenção de mercados específicos e de necessidade de diferenciação relativamente à concorrência.

Também é notório o aumento da oferta de serviços e equipamentos por parte das unidades hoteleiras de modo a poder abarcar um maior número de segmentos e públicos-alvo, onde o Turismo de Negócios assume um importante papel evidenciado através da crescente atenção dada a este produto. 
Apesar de se constatarem alguns investimentos que proporcionaram, claramente, um aumento e melhoria da oferta hoteleira existente, ainda são podemos identificar algumas lacunas. $\mathrm{O}$ alojamento de categoria superior, nomeadamente os hotéis de 5 estrelas, ainda é limitado e pouco disperso. A inexistência de alojamento de 5 estrelas nas cidades de Coimbra e Aveiro, ao contrário da cidade de Viseu onde existem duas unidades desta categoria, poderão dificultar o seu posicionamento junto de segmentos com necessidades de serviços de categoria superior, como é o caso, mais uma vez, do Turismo de Negócios. Importa referir também que a requalificação da oferta de alojamento ainda não se encontra terminada, na sequência da entrada em vigor do Decreto-Lei no 39/2008, pelo que nos próximos tempos será expectável que surjam ainda algumas mudanças, nomeadamente através da reclassificação dos empreendimentos em falta e que poderá resultar no incremento do número de hotéis de 1 e 2 estrelas.

É de realçar ainda a presença na região de grupos hoteleiros de referência nacionais (Montebelo, Pestana, Vila Galé, Tivoli, Alexandre de Almeida, Lágrimas, Belver, Eurosol, WR Hotéis) e internacionais (Meliã, Mercure, Best Western, InterContinental, Louvre Hotels, Relais \& Chateaux). No início de 2011 os grupos Alexandre de Almeida e Lágrimas anunciaram a fusão da gestão das suas unidades de hotelaria e restauração. Estes grupos abarcam algumas das mais importantes unidades de alojamento situadas em edifícios com grande significado histórico, cultural e arquitetónico, como é o caso do Buçaco Palace Hotel, do Curia Palace Hotel, do Hotel Astória de Coimbra (Alexandre de Almeida) e do Hotel Quinta das Lágrimas (grupo Lágrimas). Esta fusão evidencia a necessidade de criar novas estratégias de negócio que permitam fazer face às dificuldades económicas atuais e poderá resultar também numa melhoria da oferta de serviços, através da partilha de know how e recursos financeiros e humanos entre os dois grupos.

\section{Agradecimentos}

Este trabalho contou com o apoio financeiro da Fundação para a Ciência e a Tecnologia, no âmbito de uma bolsa de doutoramento. 


\section{Referências bibliográficas}

Decreto-Lei 39/2008 de 7 de março, Diário da República, 1.a série - N. 48, Ministério da economia e da Inovação, Lisboa.

International Congress \& Convention Association, Country and city meetings report 2011. International Association Meetings Market, Amsterdam, May 2012.

International Congress \& Convention Association, Statistics Report 2000-2010. Abstract for non-members. International Association Meetings Market, Amsterdam, August 2011.

Maisturismo 25 Years Portugal Hotel Guide 2011, Annual Publication № 25, February 2011, Maisturismo Edições e Publicidade, SA.

Maisturismo Portugal Meeting Guide \& Event Planner - The yearly Meetings Industry guide to Portugal 2011, Annual Publication no 12, November 2010, Maisturismo Edições e Publicidade, SA.

Marques, J., e Santos, N., (2011), Turismo de Negócios - Convention \& Visitors Bureau na Região Centro in Santos, N., e Cunha, L., (ed.), Trunfos de uma geografia ativa. Desenvolvimento local, ambiente, ordenamento e tecnologia, Atas do VII Congresso da Geografia Portuguesa, 26 a 28 de novembro de 2009, Coimbra, pp. 237-246.

Marques, J., e Santos, N., (2012), A metodologia Delphi aplicada ao desenvolvimento do Turismo de Negócios e à criação de um Convention and Visitors Bureau no Centro Litoral de Portugal, Revista Turismo e Desenvolvimento, Vol. 17/18 (3), pp. 1645-1655. Martins, L., (2004), Espaços de lazer e de turismo no Noroeste de Portugal, Porto, Edições Afrontamento.

Plano Estratégico Nacional do Turismo, 2007, Para o Desenvolvimento do Turismo em Portugal, Lisboa, Ministério da Economia e Inovação.

Publituris Tourism Hotel Guide 2011, Annual Special Edition no 11, Workmedia Comunicação, SA.

Santos, N., e Cunha, L., (2008). Novas oportunidades para o espaço rural. Análise exploratória no Centro de Portugal in Santos, N. e Gama, A., (ed.) Lazer. Da libertação 
do tempo à conquista das práticas, Imprensa da Universidade de Coimbra, Coimbra, pp. 209-225.

Turismo de Portugal, I.P., 2008, A Tradição Equestre como elemento de valorização da Oferta Turística in Congresso Internacional de Turismo Equestre, 15 a 17 de Maio de 2008, Alter do Chão, [http://www.turismodeportugal.pt/SiteCollectionDocuments/Turismo\%20de\%20Portu gal_Congresso\%20Int\%20Turismo\%20Equestre.pdf], consultado em 25 de Maio de 2012.

\section{Outras referências}

www.equisport.pt, acedido em 19 de maio de 2012.

www.icnb.pt, acedido em 19 de maio de 2012.

www.igespar.pt, acedido em 20 de maio de 2012.

www.maisturismo.pt, acedido em 25 de maio de 2012.

www.publituris.pt, acedido em 25 de maio de 2012.

www.termasdeportugal.pt, acedido em 25 de maio de 2012.

www.turismodeportugal.pt, acedido em 25 de maio de 2012. 